\title{
Increased extracellular local levels of estradiol in normal breast in vivo during the luteal phase of the menstrual cycle
}

\author{
Charlotta Dabrosin
}

Division of Gynaecologic Oncology, Faculty of Health Sciences, University Hospital, SE-581 85 Linköping, Sweden

(Requests for offprints should be addressed to C Dabrosin; Email: chada@ibk.liu.se)

\begin{abstract}
Estrogen exposure is a major risk factor for breast cancer. Tissue estrogen originates from the ovaries but a significant portion is also produced by enzyme activity locally in the breast itself. How these enzymes are regulated is not fully understood. The extracellular space, where the metabolic exchange and cell interactions take place, reflects the environment that surrounds the epithelium but there has been no previous study of hormone concentrations in this compartment. In the present study microdialysis was used to measure extracellular estrogen concentrations in breast tissue and abdominal subcutaneous fat in 12 healthy women in vivo. It was found that women with high plasma progesterone levels had significant increased levels of
\end{abstract}

estradiol in breast tissue compared with fat tissue (breast tissue $168 \pm 6 \mathrm{pM}$; subcutaneous fat, $154 \pm 5 \mathrm{pM}$; $P<0 \cdot 05)$, whereas women with low plasma progesterone exhibited no difference. Moreover, there was a significant correlation between local breast tissue estradiol and plasma progesterone levels $(r=0 \cdot 709, P<0 \cdot 01)$. There was no difference in estrone sulphate in breast and fat tissue regardless of progesterone levels. Estrone was not detectable. The results in this study suggest that progesterone may be one regulator in the local conversion of estrogen precursors into potent estradiol in normal breast tissue. Journal of Endocrinology (2005) 187, 103-108

\section{Introduction}

Estrogen is a key regulator of normal breast physiology as well as a major risk factor for breast carcinogenesis (Anderson et al. 1982, Rossouw et al. 2002, Beral 2003). Several studies have suggested that the concentrations of estrogen in the breast not only originate from the ovaries but that the breast itself produces a significant portion of tissue estrogens (Geisler 2003). For example, in breast cancer tissue as well as in nipple aspirate from normal breast, tissue estrogen levels have been found to be significantly higher than plasma levels (Fishman et al. 1977, Pasqualini et al. 1996, Chatterton et al. 2003). All enzymes necessary for estrogen synthesis - aromatase, steroid sulphatase and $17 \beta$-hydroxysteroid dehydrogenase $(17 \beta-H S D)$ - have been shown to be present in breast tissue (Hawkins et al. 1985, Poutanen et al. 1995, Zhou et al. 1997, Chetrite et al. 2000, Chen et al. 2002). The breast contains epithelial cells, fibroblasts and fat cells and all these various tissues express enzymes and contribute to the synthesis and conversion of estrogens (Hawkins et al. 1985, Poutanen et al. 1995, Zhou et al. 1997, Chetrite et al. 2000, Chen et al. 2002).

Although several enzymes involved in estrogen biosynthesis are characterized, the knowledge of tissue-specific expression is limited. Studies of enzyme expression do not, however, give the end result we are interested in, namely the tissue levels of the hormones. Moreover, most studies have not combined the analysis of the expression pattern of these enzymes with determinations of hormone levels and the few studies that exist have not found any consistent relationship between hormone levels and enzyme expression (van Landeghem et al. 1985, Vermeulen et al. 1986b). In previous studies of tissue concentrations of hormones, homogenate from surgical biopsies have been used. This approach has several methodological problems summarized in a recent review (Geisler 2003). In addition to the technical problems with tissue homogenate the results obtained by this technique will almost exclusively reflect intracellular levels of the hormones. The extracellular space is, however, the environment that surrounds the epithelial cells and the compartment where the metabolic exchange and cell interaction take place. Since the sources of estrogen are both systemic and local, the hormone concentrations in the extracellular compartment will reflect the total sum of hormones from various origins. Hence, a direct measurement of tissue estrogen levels in the target organ in vivo is needed. Microdialysis is a technique that mimics a blood vessel and with this technique it is possible to collect molecules from the interstitial space in a specific tissue or organ in situ. In this study microdialysis was used to determine the local levels 
of estrogens in normal human breast tissue and abdominal subcutaneous fat in healthy women with a history of regular menstrual cycles.

\section{Materials and Methods}

\section{Subjects}

12 healthy pre-menopausal women, aged 22-34 years, participated in the study. All women were free of medication and had not taken medication containing sex steroids for more than 3 months. All women had a history of regular menstrual cycles (cycle length, 27-34 days). They had had no previous breast disease or surgery and the breasts were normal on clinical examination. The local ethical committee approved the study and all women gave informed consent.

\section{Microdialysis device}

A microdialysis catheter (CMA 65; CMA/Microdialysis $\mathrm{AB}$, Solna, Sweden), which consists of a tubular dialysis membrane $(10 \mathrm{~mm}$ long $\times 0.52 \mathrm{~mm}$ in diameter; $100000 \mathrm{Da}$ cut-off) glued to the end of a double-lumen tube $(80 \mathrm{~mm}$ long $\times 0 \cdot 8 \mathrm{~mm}$ in diameter), was used. The catheters were inserted guided by a catheter for intravenous use (Venflon $1.4 \mathrm{~mm}$; BOC Ohmeda $\mathrm{AB}$, Helsingborg, Sweden). The catheters were connected to a microinfusion pump (CMA 107; CMA/Microdialysis AB) and perfused with $154 \mathrm{mM} \mathrm{NaCl}$ and $40 \mathrm{~g} / 1$ dextran-70, at a perfusion rate of $0.5 \mu \mathrm{l} / \mathrm{min}$. The solution entered the catheter through the outer tube and left it through the inner tube, from which it was collected. After a 30-min equilibration period, the outgoing perfusate was collected and stored at $-70{ }^{\circ} \mathrm{C}$ for subsequent analysis.

\section{Experimental design}

Microdialysis was performed in the luteal phase in eight women and in the follicular phase in four women. Blood samples were collected from the women at each occasion to determine estradiol and progesterone to confirm the menstrual phases (estradiol and progesterone ELISA kits; DRG Instruments GmbH, Marburg, Germany).

Mepivacaine $(5 \mathrm{mg} / \mathrm{ml})$ was administrated intracutaneously as a local anaesthetic prior to the insertion of the microdialysis catheters. One microdialysis catheter was placed in the upper lateral quadrant of the left breast and directed towards the nipple as previously described (Dabrosin et al. 1997a, 1997b, Dabrosin 2001, 2003). To be able to compare tissue levels collected by the microdialysis technique a reference catheter was placed in abdominal subcutaneous fat lateral to the umbilical region.

Microdialysis is a technique that allows continuous sampling of the extracellular space by passive diffusion of substances over a semi-permeable membrane. The recovery - that is, the amount of substances that diffuse into the perfusion fluid - depends on the membrane properties, the flow rate and the size of the compound of interest (Ungerstedt 1991). Diffusion of low-molecular-mass substances over the dialysis membrane is almost complete at low flow rates using a $30 \mathrm{~mm}$-long dialysis membrane (Rosdahl et al. 1998). However, for larger molecules the recovery over the membrane decreases and the measured levels in the microdialysis sample will not be absolute concentrations in the tissue. One way of estimating the recovery is to put the catheter into a test tube with a solution containing the molecule of interest and to measure the amount of substance leaving the catheter. This in vitro recovery can only be an estimate of the in vivo recovery since other factors such as tissue pressure and temperature will affect the diffusion of substances. In the case of sex steroids there is an almost complete recovery in vitro of the compound due to the low molecular mass of approximately $300 \mathrm{Da}$. However, in vivo $97-99 \%$ of these steroids are protein-bound and the whole complex will diffuse over the membrane. To estimate the recovery of estrogens, plasma was used as the solution to put the catheter in in vitro instead of using the hormones dissolved in a solution. With this approach the in vitro recovery could be measured of both protein-bound and free estrogens. The in vitro recovery of estradiol was $69 \pm 1 \cdot 3 \%$, and the recovery of estrone and estrone sulphate were close to 0 . This illustrates the complexity of the system and that the in vitro recovery can only be a rough estimate of the in vivo recovery since estrone sulphate was detectable in all microdialysis samples collected in vivo. In this case the main interest was to compare the levels in breast and fat tissue in the same individual and not to calculate the absolute tissue levels. Therefore all microdialysis values are given as original raw data without any re-calculations.

\section{Estradiol, estrone and estrone sulphate determinations}

Plasma was collected on each occasion using a glass tube containing $3 \cdot 8 \%$ sodium citrate as an anticoagulant, and were centrifugated and frozen at $-70{ }^{\circ} \mathrm{C}$ within $20 \mathrm{~min}$ of collection.

Microdialysate and plasma samples were analyzed for estradiol using a commercial quantitative immunoassay kit (DRG Instruments). According to the manufacturer the sensitivity of this kit is $16.8 \mathrm{pM}$ and intra-assay variation is $5 \%$.

Estrone and estrone sulphate were analyzed using RIA (Diagnostic System Laboratories, Webster, TX, USA). According to the manufacturer the estrone kit has a sensitivity of $4.44 \mathrm{pM}$ and an intra-assay variation of $5 \%$ and the estrone sulphate kit has a sensitivity of $0.028 \mathrm{nM}$ and an intra-assay variation of $4 \cdot 6 \%$. All kits were designed for a non-extracting procedure, which is an advantage when analysing the very low (microliter) volumes that are 
generated during microdialysis. When designing a microdialysis experiment with an adequate recovery over the microdialysis membrane a flow rate of approximately $0.5 \mu \mathrm{l} / \mathrm{min}$ is required (Rosdahl et al. 1998). An extraction procedure usually requires a milliliter sample volume, which is not achievable with this approach. The immunoassays developed and validated (Ranadive et al. 1998, Kraemer et al. 2003) for estrogen determinations provide therefore a possibility for measurements of estrogens in microdialysis samples collected directly from a tissue in situ. The assays used in the present study were validated against the immunoassays used for routine patient samples at the Laboratory for Clinical Chemistry at Linköping University Hospital. Moreover, quality-control samples and known plasma samples were included in each assay run and calculation of the results was performed using standard curves generated in each run. By this approach the intra-assay variations given by the manufacturer were confirmed in my laboratory. To avoid an inter-assay variation all samples were analysed in the same run. The samples were assayed in duplicate, and the mean of the two values calculated and presented in the Results section.

\section{Statistics}

Data are expressed as means \pm S.E.M. Student's $t$-test for paired observations and simple linear regression were used as appropriate. $P<0 \cdot 05$ was considered statistically significant. The study comprised 12 women and all women served as their own control to improve the power of the study.

\section{Results}

\section{Characteristics}

Plasma progesterone levels were used to verify the menstrual phase of the cycle. The normal progesterone levels in the luteal phase ranged from 13 to $79 \mathrm{nM}$. Eight of the 12 women had progesterone levels above the cut-off limit, ranging from 24 to $43 \mathrm{nM}$. The other four had progesterone levels between 1.1 and $10 \mathrm{nM}$. The characteristics of the women are summarized in Table 1.

\section{Elevated breast tissue estradiol in women with high plasma progesterone}

In women with elevated progesterone levels, the breast tissue levels of estradiol were significantly higher than estradiol in subcutaneous fat: breast tissue estradiol was $168 \pm 6 \mathrm{pM}$ and that of subcutaneous fat was $154 \pm 5 \mathrm{pM}$ $(P<0 \cdot 05$; Fig. 1A). Three out of four women with low plasma progesterone had lower levels of estradiol in breast tissue compared with fat but there was no significant difference by these four women since one had higher
Table 1 Hormone levels in plasma of 12 pre-menopausal women

\begin{tabular}{|c|c|c|c|c|}
\hline & $\begin{array}{l}\text { Estradiol } \\
(\mathrm{pM})\end{array}$ & $\begin{array}{l}\text { Progesterone } \\
(\mathrm{nM})\end{array}$ & $\begin{array}{l}\text { Estrone sulphate } \\
(\mathrm{nM})\end{array}$ & $\begin{array}{l}\text { Estrone } \\
(\mathrm{pM})\end{array}$ \\
\hline \multicolumn{5}{|c|}{ Subject } \\
\hline 1 & 262 & 43 & $8 \cdot 2$ & 165 \\
\hline 2 & 213 & 24 & $6 \cdot 4$ & 166 \\
\hline 3 & 251 & 43 & $6 \cdot 5$ & 149 \\
\hline 4 & 337 & 32 & 10 & 405 \\
\hline 5 & 205 & 40 & $7 \cdot 8$ & 184 \\
\hline 6 & 268 & 37 & $7 \cdot 7$ & 166 \\
\hline 7 & 214 & 40 & $8 \cdot 5$ & 150 \\
\hline 8 & 387 & 31 & $5 \cdot 1$ & 182 \\
\hline 9 & 247 & $1 \cdot 4$ & 11 & 219 \\
\hline 10 & 331 & $1 \cdot 1$ & $6 \cdot 6$ & 172 \\
\hline 11 & 225 & $1 \cdot 2$ & $6 \cdot 0$ & 172 \\
\hline 12 & 181 & 10 & $5 \cdot 4$ & 111 \\
\hline
\end{tabular}

levels in breast compared with fat $(P>0 \cdot 05$; Fig. 1B). This result should, however, be interpreted with care due to the low number of women in this group. There was a wide range of tissue levels between the individual women; therefore, breast tissue estradiol was calculated as a percentage of fat estradiol in the same individual. A significant correlation was found between the amount of breast tissue estradiol/fat tissue estradiol and plasma progesterone levels $(P<0 \cdot 01$; Fig. 2).

There were no differences between estrone sulphate levels regardless of plasma progesterone (breast tissue, $0.054 \pm 0.018 \mathrm{nM} ; \quad$ fat,$\quad 0.222 \pm 0.129 \mathrm{nM} ; \quad P=0.4)$. Estrone was not detectable in the microdialysis samples.

\section{Discussion}

This study showed that women with high plasma progesterone levels, verifying the mid-luteal phase of the menstrual cycle, had significantly higher extracellular levels of estradiol in breast tissue in vivo compared with subcutaneous fat. In women with low progesterone levels, representing non-ovulating women or women in the follicular phase, there was no difference in estradiol levels between breast tissue and subcutaneous fat. Plasma progesterone correlated significantly with local breast tissue estradiol. Together these results suggest that progesterone affects the local conversion of estrogens in normal breast tissue. Moreover, this study introduces microdialysis for measurement of local tissue levels of estrogens.

The $17 \beta-H S D$ enzymes catalyze the interconversion of low-activity estrogens such as estrone and high-activity estrogens such as estradiol. At least 10 isoenzymes of $17 \beta$-HSD have been characterized, which differ in their reductive and oxidative catalyzing capacities (Adamski \& Jakob 2001, Geisler 2003). The isoenzyme 17ß-HSD type 1 seems to be responsible for the conversion of estrone to 

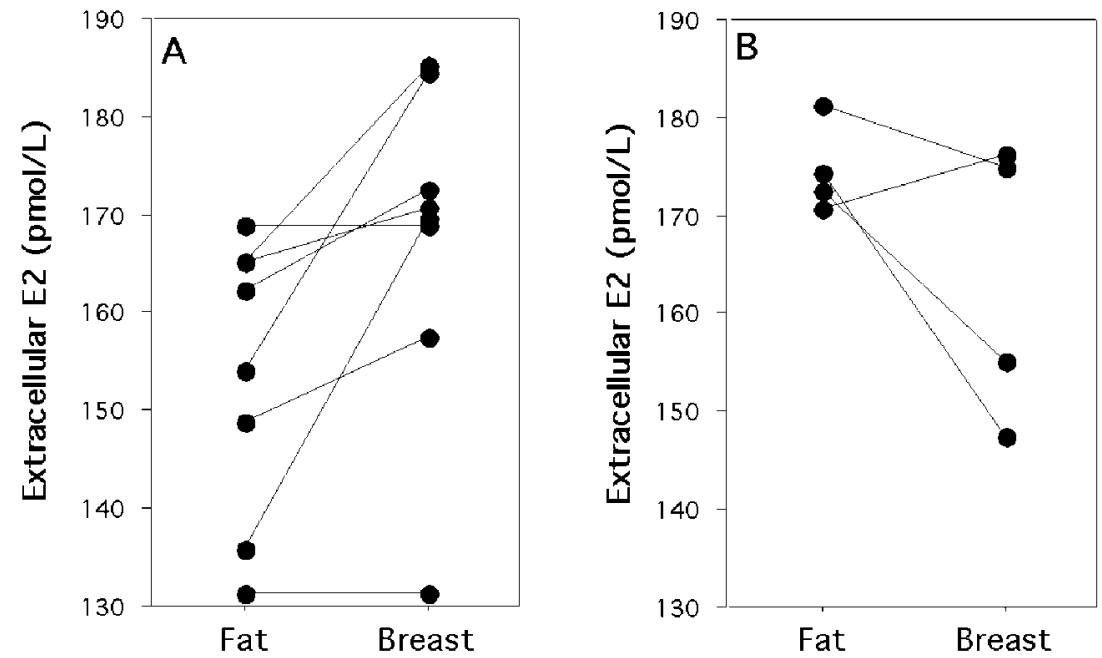

Figure 1 Extracellular estradiol in breast and fat tissue. (A) Tissue estradiol (E2) in eight women with plasma progesterone levels, representing the luteal phase of the menstrual cycle. Levels were significantly increased in breast tissue $(168 \pm 6 \mathrm{pM})$ compared with subcutaneous fat $(154 \pm 5 \mathrm{pM} ; P<0 \cdot 05)$. (B) Tissue estradiol in four women with low plasma progesterone, representing the follicular phase of the menstrual cycle. There was no significant difference between the levels; breast tissue, $163 \pm 7 \cdot 1 \mathrm{pM}$; fat tissue,

$174 \pm 2 \cdot 3 \mathrm{pM}(P=0 \cdot 2)$.

estradiol and therefore is considered as the main factor contributing to high tissue levels of estradiol in breast cancer (Vermeulen et al. 1986a). Several of the 17 $\beta-H S D$ enzymes have also been detected in normal breast tissue (Soderqvist et al. 1998, Miettinen et al. 1999) but previous investigations have not found any correlation between enzyme expression and hormone levels (van Landeghem et al. 1985, Vermeulen et al. 1986b). This emphasizes the need for determination of the estrogen levels in the target organ before any interpretations of the physiological relevance of the expression of various enzymes can be made. As shown in this study, microdialysis can be used for in vivo

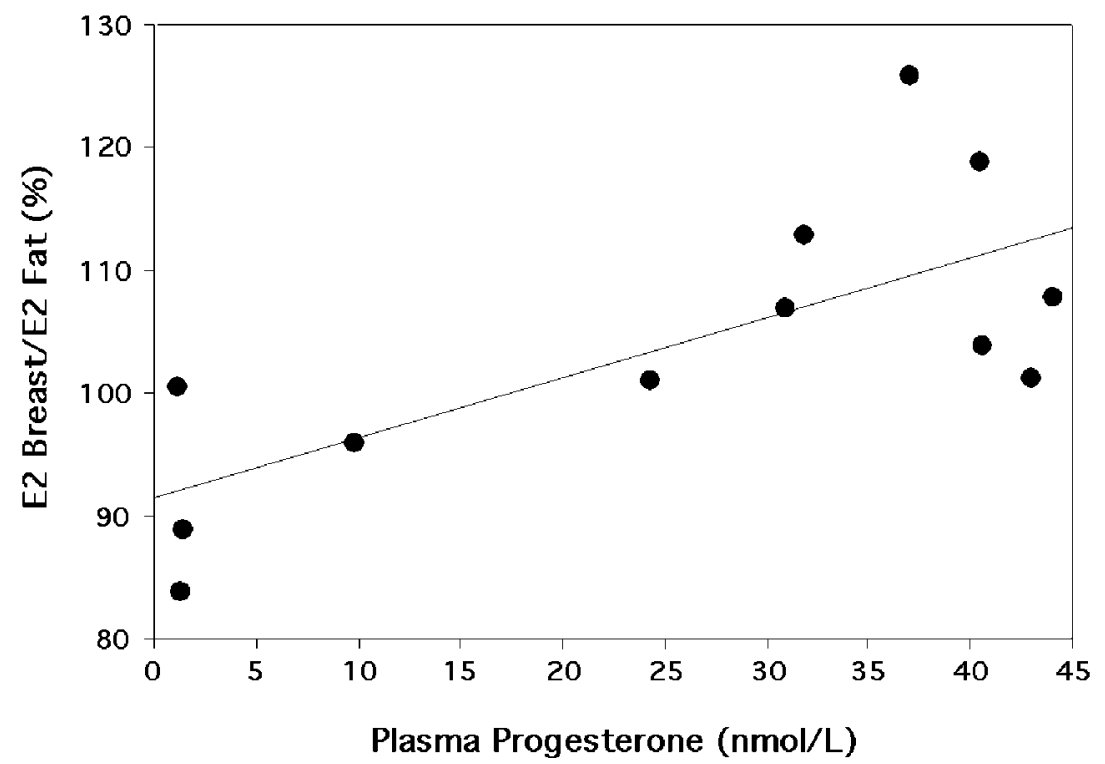

Figure 2 Correlation between plasma progesterone and the percentage of breast tissue estradiol (E2) to fat tissue estradiol. Linear regression between the percentage of breast estradiol/fat estradiol and plasma progesterone levels with progesterone as an independent variable and tissue estradiol as a dependent variable: $r=0 \cdot 709, t=3 \cdot 18, P<0 \cdot 01$. 
measurements of estrogens and will be of significant value in future studies in this field of research.

In the present study the women with high progesterone levels exhibited higher breast tissue levels of estradiol compared with fat tissue. This may suggest increased enzyme activities that favour the conversion of estrone to estradiol under the influence of progesterone. This is in line with previous studies which have shown a positive correlation between serum progesterone levels and expression of $17 \beta-H S D$ type 1 in breast cancer tissue (Poutanen et al. 1990, 1992a, 1992b). However, there is a controversy of progestin regulation of this enzyme since other authors have demonstrated decreased reductive activity of $17 \beta-$ HSD leading to decreased formation of estradiol after exposure of progestins to breast cancer cells in culture (Chetrite \& Pasqualini 2001). These studies have been performed in culture of breast cancer cells using relatively high concentrations of synthetic progestins and should be interpreted with caution regarding the regulation of these enzymes in normal breast tissue in vivo exposed to physiological levels of the natural occurring progesterone.

The 12 women in this study did not exhibit any difference in estrone sulphate concentrations between breast and fat tissue regardless of plasma progesterone concentrations. Although estradiol is the most potent of the endogenous estrogens and has been shown to be the most important determinant of breast cancer risk (Key 1999), estrone sulphate is the most abundant estrogen and the major precursor for local biosynthesis of estradiol. It has been shown that the estrone sulphatase activity is high in estrogen receptor positive breast cancer cell lines whereas hormone-independent cell lines express very low sulphatase activity (Chetrite \& Pasqualini 2001). In normal breast tissue, adjacent to tumour tissue, estrone sulphatase activity has been shown to be elevated compared with the tumour levels (Chetrite et al. 2000). This suggests that normal breast tissue expresses sulphatase activity but very little is known about its regulation. The present data do not suggest any difference in the activity of estrone sulphatase in breast tissue compared with fat tissue but this has to be investigated further before any conclusions can be made. Estrone was not detectable with the $10 \mathrm{~mm}$-long dialysis membrane used in this study. This could probably be overcome in future studies by using a longer microdialysis membrane and thereby increasing the recovery of estrone over the membrane.

The regulation of the enzymes involved in local biosynthesis of estrogen in peripheral tissues is complex and not fully understood. All the different cell types that exist in normal breast tissue and breast cancer including tissue macrophages and lymphocytes can regulate the enzymes involved in estrogen formation and inactivation. Several cytokines secreted by these cell types on a local level have been shown to influence the expression of $17 \beta-\mathrm{HSD}$, estrone sulphatase and aromatase (Turgeon et al. 1998, Purohit et al. 2002, 2003). This complex regulation necessitates research on whole tissue, preferably in vivo, rather than cell culture studies. Moreover, very few studies have combined detection and quantification of enzyme activities with actual measurements of hormone levels, partly because of a lack of a suitable technique for these determinations. The microdialysis technique opens up new possibilities in such investigations.

High tissue levels of estradiol have to be considered as breast cancer-promoting for both their effects on proliferation and other non-receptor-mediated effects of estradiol, such as the carcinogenic effect of the metabolite 4hydroxyestradiol (Liehr 2000). The high levels of estradiol in breast tissue in the luteal phase and the correlation between local breast tissue levels of estradiol and plasma progesterone shown in this study suggest that progesterone may be one regulator of local conversion of estrogen precursors into potent estradiol in normal breast tissue.

\section{Funding}

This study was supported by grants from Swedish Cancer Society and Research Funds of Linköping University Hospital. The author declares that there is no conflict of interest that would prejudice the impartiality of this scientific work.

\section{References}

Adamski J \& Jakob FJ 2001 A guide to 17 beta-hydroxysteroid dehydrogenases. Molecular and Cellular Endocrinology 171 1-4.

Anderson TJ, Ferguson DJ \& Raab GM 1982 Cell turnover in the 'resting' human breast: influence of parity, contraceptive pill, age and laterality. British Journal of Cancer 46 376-382.

Beral V 2003 Breast cancer and hormone-replacement therapy in the Million Women Study. Lancet 362 419-427.

Chatterton Jr RT, Geiger AS, Gann PH \& Khan SA 2003 Formation of estrone and estradiol from estrone sulfate by normal breast parenchymal tissue. Journal of Steroid Biochemistry and Molecular Biology 86 159-166.

Chen S, Itoh T, Wu K, Zhou D \& Yang C 2002 Transcriptional regulation of aromatase expression in human breast tissue. Journal of Steroid Biochemistry and Molecular Biology 83 93-99.

Chetrite GS \& Pasqualini JR 2001 The selective estrogen enzyme modulator (SEEM) in breast cancer. Journal of Steroid Biochemistry and Molecular Biology 76 95-104.

Chetrite GS, Cortes-Prieto J, Philippe JC, Wright F \& Pasqualini JR 2000 Comparison of estrogen concentrations, estrone sulfatase and aromatase activities in normal, and in cancerous, human breast tissues. Journal of Steroid Biochemistry and Molecular Biology 72 23-27.

Dabrosin C 2001 Technical aspects of microdialysis of human breast. Scandinavian Journal of Clinical and Laboratory Investigation $\mathbf{6 1}$ 269-272.

Dabrosin C 2003 Variability of vascular endothelial growth factor in normal human breast tissue in vivo during the menstrual cycle. Journal of Clinical Endocrinology and Metabolism 88 2695-2698.

Dabrosin C, Hallstrom A, Ungerstedt U \& Hammar M 1997a Microdialysis of human breast tissue during the menstrual cycle. Clinical Science (London) 92 493-496.

Dabrosin C, Ollinger K, Ungerstedt U \& Hammar M 1997 b Variability of glutathione levels in normal breast tissue and 
subcutaneous fat during the menstrual cycle: an in vivo study with microdialysis technique. Journal of Clinical Endocrinology and Metabolism 82 1382-1384.

Fishman J, Nisselbaum JS, Menendez-Botet CJ \& Schwartz MK 1977 Estrone and estradiol content in human breast tumors: relationship to estradiol receptors. Journal of Steroid Biochemistry 8 893-896.

Geisler J 2003 Breast cancer tissue estrogens and their manipulation with aromatase inhibitors and inactivators. Journal of Steroid Biochemistry and Molecular Biology 86 245-253.

Hawkins RA, Thomson ML \& Killen E 1985 Oestrone sulphate, adipose tissue, and breast cancer. Breast Cancer Research and Treatment 6 75-87.

Key TJ 1999 Serum oestradiol and breast cancer risk. Endocrine-Related Cancer 6 175-180.

Kraemer GR, Kraemer RR, Ogden BW, Kilpatrick RE, Gimpel TL \& Castracane VD 2003 Variability of serum estrogens among postmenopausal women treated with the same transdermal estrogen therapy and the effect on androgens and sex hormone binding globulin. Fertility and Sterility 79 534-542.

van Landeghem AA, Poortman J, Nabuurs M \& Thijssen JH 1985 Endogenous concentration and subcellular distribution of estrogens in normal and malignant human breast tissue. Cancer Research $\mathbf{4 5}$ 2900-2906.

Liehr JG 2000 Is estradiol a genotoxic mutagenic carcinogen? Endocrine Review 21 40-54.

Miettinen M, Mustonen M, Poutanen M, Isomaa V, Wickman M, Soderqvist G, Vihko R \& Vihko P 199917 Beta-hydroxysteroid dehydrogenases in normal human mammary epithelial cells and breast tissue. Breast Cancer Research and Treatment 57 175-182.

Pasqualini JR, Chetrite G, Blacker C, Feinstein MC, Delalonde L, Talbi M \& Maloche C 1996 Concentrations of estrone, estradiol, and estrone sulfate and evaluation of sulfatase and aromatase activities in pre- and postmenopausal breast cancer patients. Journal of Clinical Endocrinology and Metabolism 81 1460-1464.

Poutanen M, Isomaa V, Kainulainen K \& Vihko R 1990 Progestin induction of 17 beta-hydroxysteroid dehydrogenase enzyme protein in the T-47D human breast-cancer cell line. International Journal of Cancer 46 897-901.

Poutanen M, Isomaa V, Lehto VP \& Vihko R 1992a Immunological analysis of 17 beta-hydroxysteroid dehydrogenase in benign and malignant human breast tissue. International Journal of Cancer $\mathbf{5 0}$ 386-390.

Poutanen M, Moncharmont B \& Vihko R $1992 b 17$ betahydroxysteroid dehydrogenase gene expression in human breast cancer cells: regulation of expression by a progestin. Cancer Research 52 290-294.

Poutanen M, Isomaa V, Peltoketo H \& Vihko R 1995 Regulation of oestrogen action: role of 17 beta-hydroxysteroid dehydrogenases. Annals of Medicine 27 675-682.
Purohit A, Newman SP \& Reed MJ 2002 The role of cytokines in regulating estrogen synthesis: implications for the etiology of breast cancer. Breast Cancer Research 4 65-69.

Purohit A, Singh A, Ghilchik MW, Serlupi-Crescenzi O \& Reed MJ 2003 Inhibition of IL-6+IL-6 soluble receptor-stimulated aromatase activity by the IL-6 antagonist, Sant 7 , in breast tissue-derived fibroblasts. British Journal of Cancer 88 630-635.

Ranadive GN, Mistry JS, Damodaran K, Khosravi MJ, Diamandi A, Gimpel T, Castracane VD, Patel S \& Stanczyk FZ 1998 Rapid, convenient radioimmunoassay of estrone sulfate. Clinical Chemistry 44 244-249.

Rosdahl H, Hamrin K, Ungerstedt U \& Henriksson J 1998 Metabolite levels in human skeletal muscle and adipose tissue studied with microdialysis at low perfusion flow. American Journal of Physiology - Endocrinology and Metabolism 274 E936-E945.

Rossouw JE, Anderson GL, Prentice RL, LaCroix AZ, Kooperberg C, Stefanick ML, Jackson RD, Beresford SA, Howard BV, Johnson $\mathrm{KC}$ et al. 2002 Risks and benefits of estrogen plus progestin in healthy postmenopausal women: principal results From the Women's Health Initiative randomized controlled trial. Journal of the American Medical Association 288 321-333.

Soderqvist G, Poutanen M, Wickman M, von Schoultz B, Skoog L \& Vihko R 199817 Beta-hydroxysteroid dehydrogenase type 1 in normal breast tissue during the menstrual cycle and hormonal contraception. Journal of Clinical Endocrinology and Metabolism 83 $1190-1193$

Turgeon C, Gingras S, Carriere MC, Blais Y, Labrie F \& Simard J 1998 Regulation of sex steroid formation by interleukin-4 and interleukin-6 in breast cancer cells. Journal of Steroid Biochemistry and Molecular Biology 65 151-162.

Ungerstedt U 1991 Microdialysis-principles and applications for studies in animals and man. Journal of Internal Medicine 230 365-373.

Vermeulen A, Deslypere JP \& Paridaens R 1986a Steroid dynamics in the normal and carcinomatous mammary gland. Journal of Steroid Biochemistry 25 799-802.

Vermeulen A, Deslypere JP, Paridaens R, Leclercq G, Roy F \& Heuson JC 1986b Aromatase, 17 beta-hydroxysteroid dehydrogenase and intratissular sex hormone concentrations in cancerous and normal glandular breast tissue in postmenopausal women. European Journal of Cancer and Clinical Oncology 22 $515-525$.

Zhou D, Zhou C \& Chen S 1997 Gene regulation studies of aromatase expression in breast cancer and adipose stromal cells. Journal of Steroid Biochemistry and Molecular Biology 61 273-280.

Received 5 April 2005

Accepted 19 July 2005

Made available online as an

Accepted Preprint 3 August 2005 